Original Research Paper

\title{
Performance Comparison of Passive Fault Tolerant Control Strategy with PI and Fuzzy Control of Single-Tank Level Process with Sensor and System Fault
}

\author{
Himanshukumar R. Patel and Vipul A. Shah \\ Instrumentation and Control, Dharmsinh Desai University, Nadiad, India
}

\section{Article history}

Received: 21-03-2018

Revised: 30-04-2018

Accepted: 21-05-2018

Corresponding Author: Himanshukumar R. Patel Instrumentation and Control, Dharmsinh Desai University, Nadiad, India

Email: himanshupatelp32@gmail.com himanshupatel.ic@ddu.ac.in

\begin{abstract}
Fault-Tolerant Control (FTC) strategy has gain maximum attention in recent years in chemical industries due to economical and safety hazards perspective. Targeting at the decreasing control performance of the single-tank level control process under the constraint of system and sensor faults, this article presents model-based Passive Fault-Tolerant Control (PFTC) strategy which are based on conventional and artificial intelligence control. The deviation between system outputs and model output are called residuals and are used to detect and identify faults. The mathematical model of single-tank level system is derived from real time process data using process reaction curve method. The paper discusses about the performance comparison between model-based PFTC using fuzzy logic and conventional proportional Plus Integral controller (PI). The proposed PFTC strategy is applied on single-tank level control process with system and sensor faults and verifies the performance of PFTC using fuzzy logic plus conventional PI control and other PFTC configuration. Proposed PFTC using fuzzy logic plus PI control gives better control performance even though fault occurs in the system. The control performance of different PFTC strategies are measured in terms of Mean Square Error (MSE), Root Mean Square Error (RMSE) and Mean Absolute Error (MAE) indices.
\end{abstract}

Keywords: Passive Fault-Tolerant Control, Fuzzy Logic, PI Control, Sensor Fault, System Fault

\section{Introduction}

Fault Tolerant Control (FTC) comprises diagnosis with control methods to handle faults in smart way. The aim is to prevent that simple faults develop into severe failure and hence increase plant availability and reduce the risk of safety hazards (Jiang, 2010). Generally 'fault' is defined as an unpredicted variation of the system functionality. We are concerned to detection, diagnosis of faults in an engineering system, whether they occur in the plant and control instrument (Sensor and actuators) or in the components of the process itself. In any industrial closed loop system there are sensors, controller, system or component (actuator, pipe, leak...etc.) faults presented in (Gao et al., 2015) (Patel and Shah, 2018) the diagram shown in Fig. 1.

Any Faults deteriorate the system performance as well as stability.

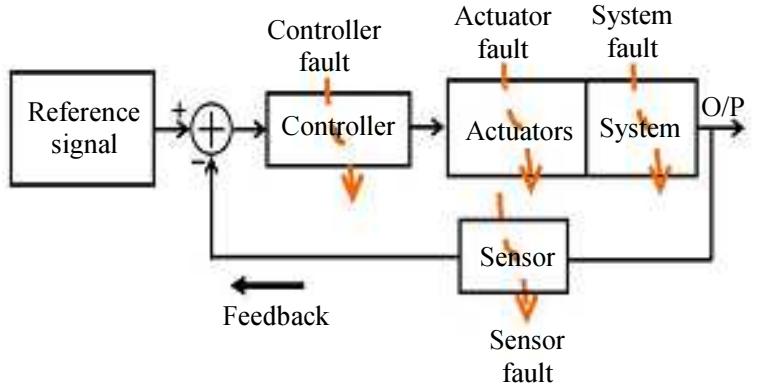

Fig. 1: Closed loop control system with posibal faults

Many engineering systems, such as chemical process, aero engines, manufacturing systems, electric machines and industrial electronic equipment are safety-critical systems. There is an ever-increasing demand on reliability and safety of industrial systems subjected to potential process abnormalities and different faults. As a 
result, it is essential to detect and recognize any kind of deformities and fault as early as possible and implement fault tolerant operation for improving performance degradation and avoiding hazardous situation (Gao et al., 2015). The Fault-Tolerant Control (FTC) is an efficient technique which can increase the system reliability in terms of all aspects in modern complex engineering systems (Ding, 1997; Isermann, 2006; Blanke et al., 2006). The prime objective to establish FTC technique is, to tolerate faults in a system component or itself system and maintaining control performance to the acceptable level with system stability during the time of fault occurrence. The FTC technique was introduced way back in early 70's, substantial work has been done (Niederlinski, 1971). In general, FTC can be classified into two types: The Active Fault Tolerant Control (AFTC) and Passive Fault Tolerant Control (PFTC). AFTC works with updating controller structure according to signal provide by fault diagnosis mechanism at the same time PFTC works on monochrome controller structure to deal with the potential faults in system. The PFTC is simplest to implement because of simple controller structure as compared to AFTC. There is no need of fault diagnosis in PFTC with considering to the fact that it has powerful to set of predefined faults (Korbicz et al., 2004). Many successful application on diffrent safety critcal system addressed in the articles (Xu et al., 2015; Aberkane et al., 2008; Zhang and Jiang, 2008).

Fault tolerant methods have been applied to CSTR tank in (Li and Wang, 2014), three-tank and four-tank benchmark system in a few latest research works. Some cases are stated in (Casavola et al., 2010) where fault tolerant has been implemented on a four-tank system using Command Governor (CG) controller. In (Orani et al., 2009) high order sliding mode observers have been used for a three-tank system. (Mendoca et al., 2007) have used predictive control and fuzzy logic to design a fault tolerant control for a three-tank benchmark. In (Dardinier-Maron et al., 1999) using feedback linearization, an approach has been proposed for fault tolerant control in a three-tank benchmark. Some other works in this respect are (Noura et al., 2000; Diaoa and Passino, 2002; Puig et al., 2005). More research is attributed towerds two-tank and three tank level control system with interacting and non-interacting system configuration as these are highly used in chemical, food processing industries etc. To improving system reliability, efficacy and avoiding hazardous condition in two-tank and three-tank level control system, in recent time some researcher addressing these problem very nicely. Orani et al. (2009) robust fault detection strategy has been proposed for a three-tank system using sliding mode observer. (Capiluppi and Paoli, 2005) proposed a model of distribute fault tolerant control and implemented on two-tank benchmark system with different faults. Artificial intelligence technique (fuzzy Logic) is combined with Model Predictive Control (MPC) for designing fault tolerant control scheme of three-tank nonlinear system with two fault constraintt (Mendonca et al., 2008). For DTS200 threetank system a finite-time convergent fault tolerant control was apply for varying fault sources, process disturbances, through inter-tank connections in (Basin et al., 2015). Parikh et al. (2017) proposed and implemented Linear Quadratic Gaussian Control (LQG) with the Non-linear Model Predictive Control (NMPC) for three-tank interacting system and compared the performance for the servo plus disturbance rejection and regulatory control, process disturbance is adding through the interacting flow control valve. (Patel and Shah, 2018) have found a new strategy for the passive fault tolerant control using artificial neural network with conventional PI feedback control for single-tank noninteracting level control system.

To overcome the effect of the faults in the system performance, this article presents effective Passive FTC (PFTC) strategy with conventional and fuzzy control on single-tank level process with system and sensor faults. The objective of this paper is to design a Passive Faulttolerant controller for a single-tank level system with system (leak) and sensor faults. Artificial intelligences such as fuzzy logic control are used for developing fault tolerant control system. Artificial intelligences have been successfully used for pattern recognition and as such it can be suitable for use in fault diagnosis of processes (Hussain et al., 2007). In addition to this, the article also compares the results of simulation of PFTC for singletank level system for conventional feedback and combination of feedback and artificial intelligence control. This paper focuses on comparative study of various PFTC strategy using PI and Fuzzy logic controller when single or multiple faults occur with different magnitude in terms of different error indices. Types of faults applied in to the system are System (leak) and measurement component (Sensor bias).

This paper is organized as follows: Section 2 deals with process description, Section 3 deals with proposed FTC strategy using conventional method (Closed loop PID control) and fuzzy control, section 4 shown Simulink model diagram in Matlab, section 5 shown simulation results with different faults and magnitude, section 6 discusses results obtained from simulation, then three different PFTC control techniques are compared with each other and section 6 concludes the study.

\section{Process Description}

The process shown in figure is the Single-Tank level control system which consists of one water tank, one sump, pneumatic Control Valve $\left(\mathrm{CV}_{1}\right)$ and one electric 
pump. Also for system fault generation leak provision is kept in tank via valve. The system is shown in Fig. 2 . The pump operates at $230 \mathrm{AC}$ volts and provides constant flow. The output is the water height in the tank. The height of tank is $100 \mathrm{~cm}$. The single-tank level control process is very commonly in any chemical process.

Model of single-tank system with Mass balance and Bernoulli's law yields:

$\frac{d h}{d t}=\left(\frac{f_{i}}{a}-\frac{h}{(r+a)}\right)$

$\frac{d h}{d t}=\left[\left(\frac{f_{i}}{a}-\frac{h}{(r+a)}\right)-\frac{h_{1}}{\left(r_{1}+a_{1}\right)}\right]$

Where:

$a=$ Cross-section of tank outlet

$a_{1}=$ Cross-section of leak outlet

$r \quad=$ Diameter of restriction (orifice)

$r_{1}=$ Diameter of restriction of leak fault

$h=$ Water level in tank

$h_{1}=$ Leak height

$f_{i}=$ Inlet water flow in tank

$\frac{d h}{d t}=$ Change of rate of height in tank

"Equation 2" defines the system fault model. It is for system (leak) fault generated at height $h_{1}$. The model of the single-Tank system is derived from either physical principles or system identification technique. In this study, model of system is derived by physical principles technique and is given by following equation:

$$
G_{p}(s)=\frac{5}{100 s+1}
$$

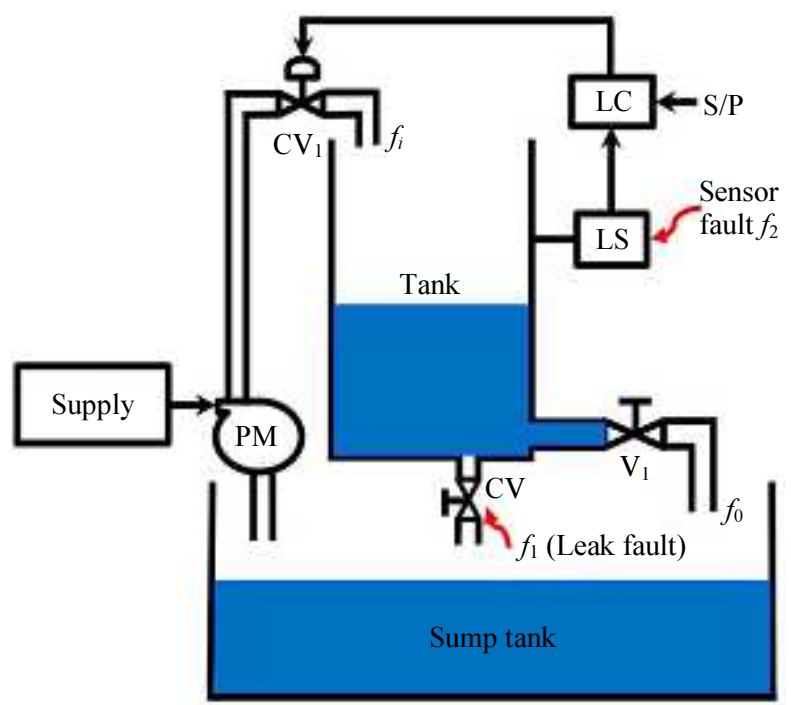

Fig. 2: Single-tank level control process system
In single-tank level control system two faults are considered: one is system (leak) fault $f_{1}$ and second one is sensor bias fault $f_{2}$. At the designing stage of the PFTC controller, prior knowledge of these two faults are considered and accordingly controller is designed.

\section{Controller Design Methods}

\section{Conventional PI Controller}

Figure 3 show a conventional feedback control system where the PI controller, is connected to the plant, while the summing point, where it is compared with the references input. The output is obtained by

$Y(s)=\frac{G_{c}(s) G_{p}(s)}{1+G_{c}(s) G_{p}(s) K(s)} R(s)$

\section{Proposed Model-based PFTC Strategy Using Conventional PI and Fuzzy Control}

Figure 4 represents the model based system fault tolerant control system where $G_{p}(s)$ is the controlled system or plant and the $\tilde{G}_{p}(s)$ is plant model. $K(s)$ is a sensor gain while $G_{c}(s)$ is a conventional PID controller model. The design related signal that consist are input command $R(s)$, error $e(s)$, control signal $u(s)$, actual output $C(s), Y(s)$ feedback sensor output $Y_{P}(s)$ plant model output and residual signal $f(s)$.

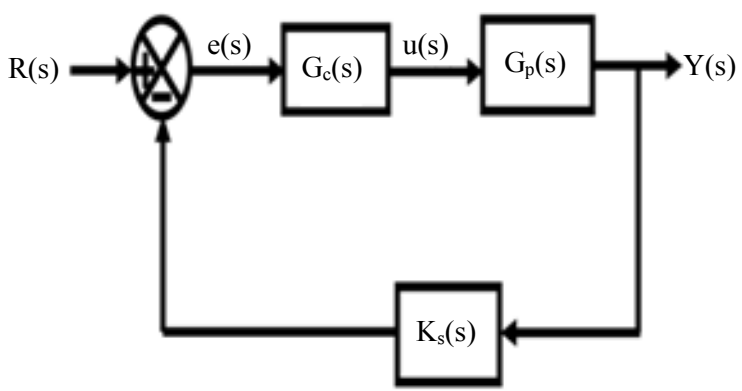

Fig. 3: Conventional Feedback Control System

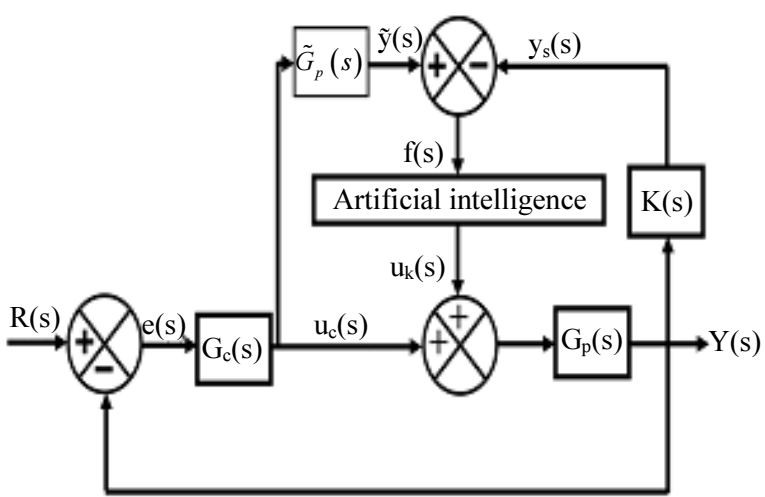

Fig. 4: Passive FTC Strategy with Conventional PI and Fuzzy Control 
The suggested PFTC control strategy is capable of maintaining desired control performance when no fault is present but it also able to maintain the performance of the system when system (leak) and sensor faults occur.

\section{Model based PFTC Using Fuzzy Control}

Fuzzy logic is a methodology to compute "degrees of truth" rather than the usual "true or false" on the basis of predefined linguistic statements in the form of "IF-THEN statements which are called fuzzy rules. This paper attributes such rules in the passive FTC strategy and resulting to generate controller output $u_{k}(s)$. Resultant passive FTC strategy on single-tank level process is shown in Fig. 4. Residue $f(s)$ and control output $u_{k}(s)$ are normalized by following equation:

$$
\begin{aligned}
& f(s)=f^{\prime}(s)=\left\{\left(\frac{\text { residue }}{\text { std_error }(\text { residue })}\right)\right\} \\
& u_{k}(s)=u_{k}^{\prime} *\left(S t d_{\text {Mean }}\right)
\end{aligned}
$$

The basic Fuzzy Logic Controller (FLC) is shown in Fig. 5. It is distrubuted in four parts: one is fuzzification which implies that it is the process of changing a real scalar value into a fuzzy value., second one is rule base which has various fuzzy rule bases and third one is FIS which contains IF THEN fuzzy rule bases and last one is defuzzification. It is the process of changing a fuzzy value into a real scalar. At the input side of the FIS, normalized value of residue $\mathrm{f}(\mathrm{s})$ is applied which is given by "Equation 5 " and "Equation 6" gives denormalized value of output $u_{k}(s)$ from FIS.

The parameters $f(s)$ and $u_{k}(s)$, are determined by a set of fuzzy rules of the form if $f(s)$ is $A_{i}$, then $u_{k}(s)$ is $B_{i}$ where, $i=1,2 \ldots m$. Here, $A_{i}, B_{i}$ are fuzzy sets on the corresponding supporting sets. The Membership Function (MF) of these fuzzy sets for $f(s)$ and $u_{k}(s)$ are shown in Fig. 6 and 7. Choosing the fuzzy rules is the most important issue. In this study, the fuzzy rules are taken in such a way that control response of the system nullify the system and sensor faults satisfying the control performance. They are taken as in the Table 1 .

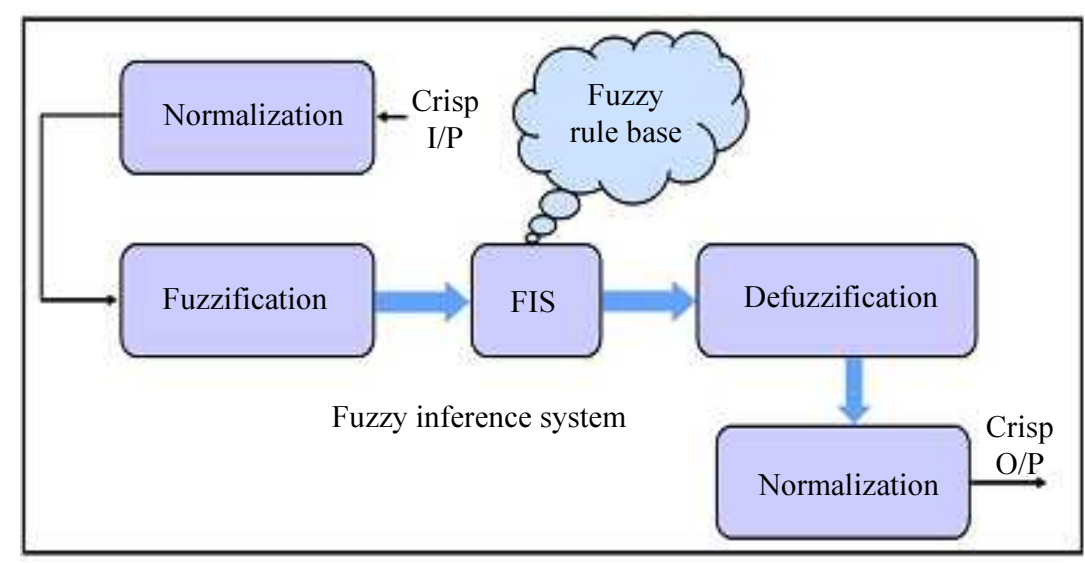

Fig. 5: Fuzzy Inference System (FIS)

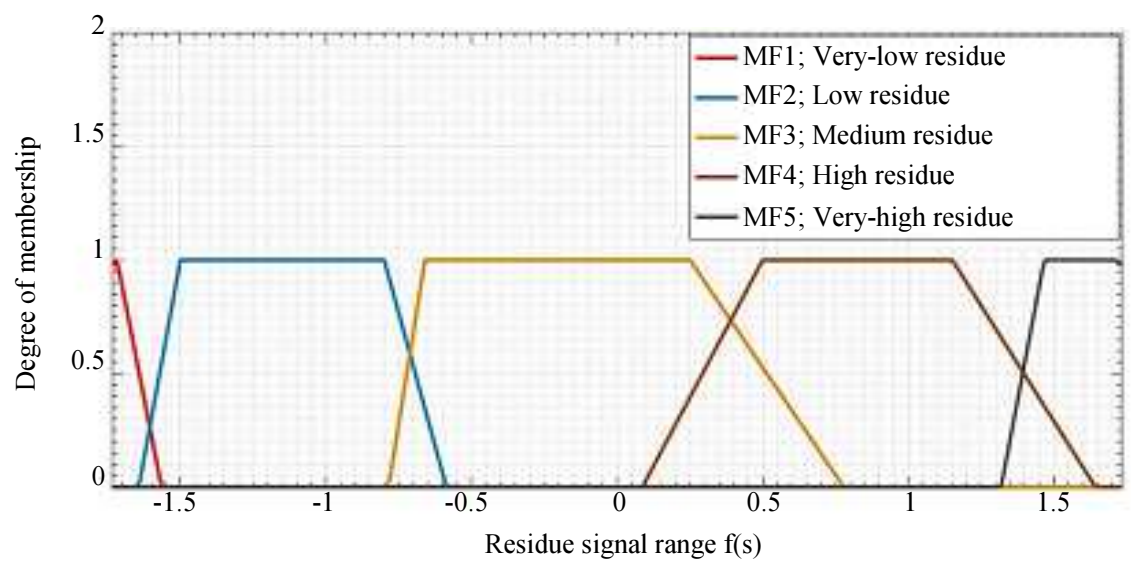

Fig. 6: Membership function for residue signal $f(s)$ 


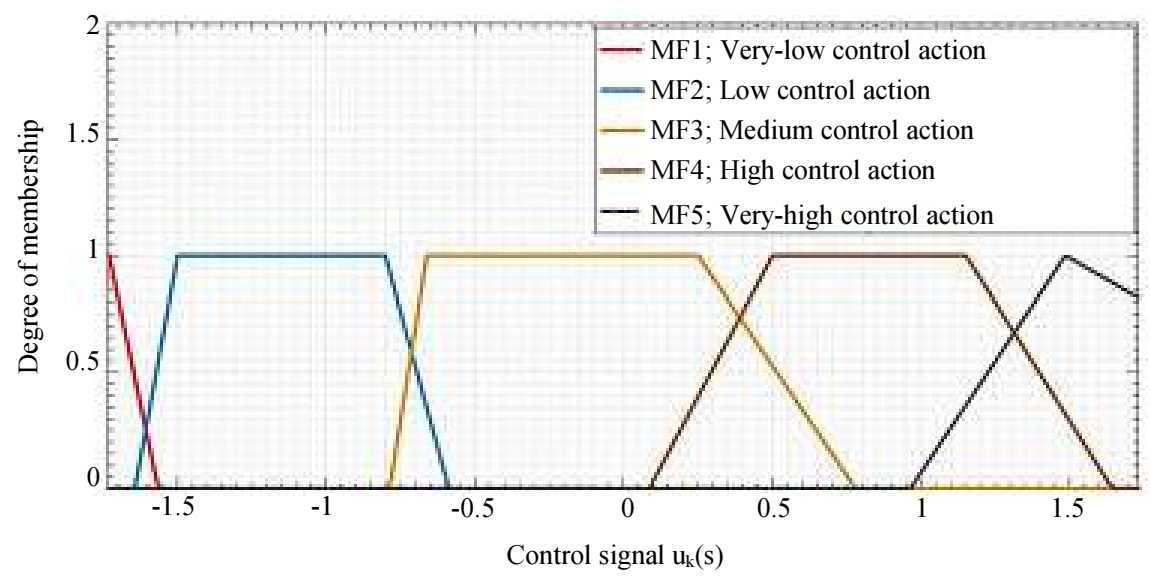

Fig. 7: Membership function for control signal $u_{k}(s)$

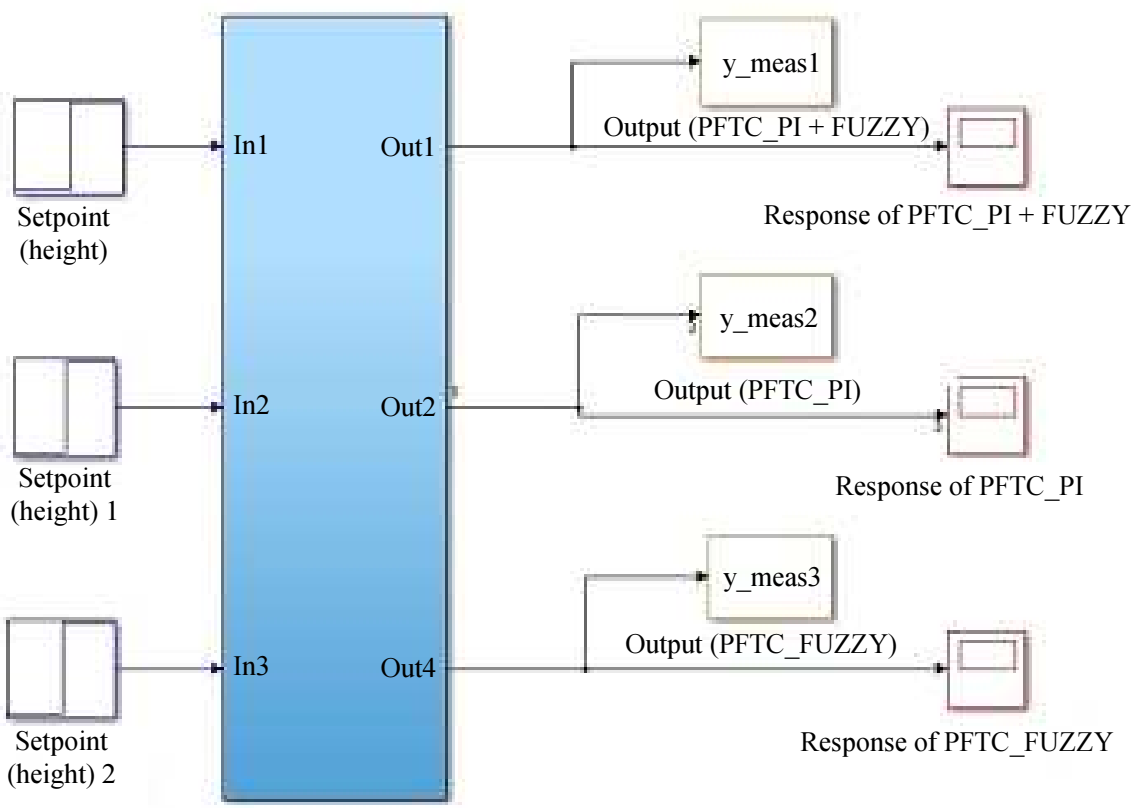

Subsystem PFTC

Fig. 8: MATLAB Simulink block for three PFTC Strategies on Single-Tank level control process with system and sensor bias faults

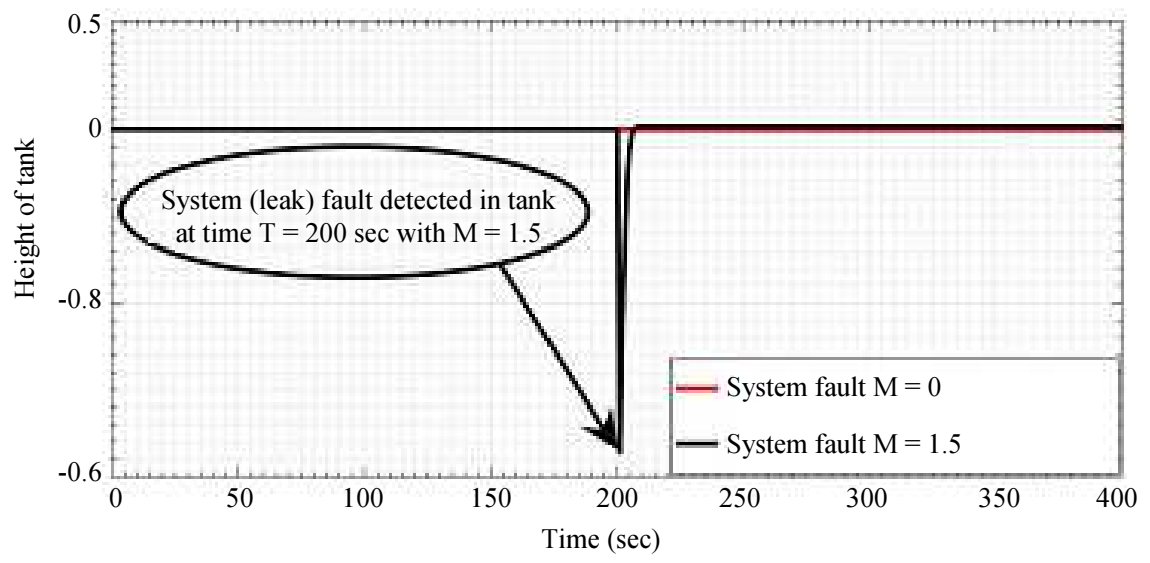




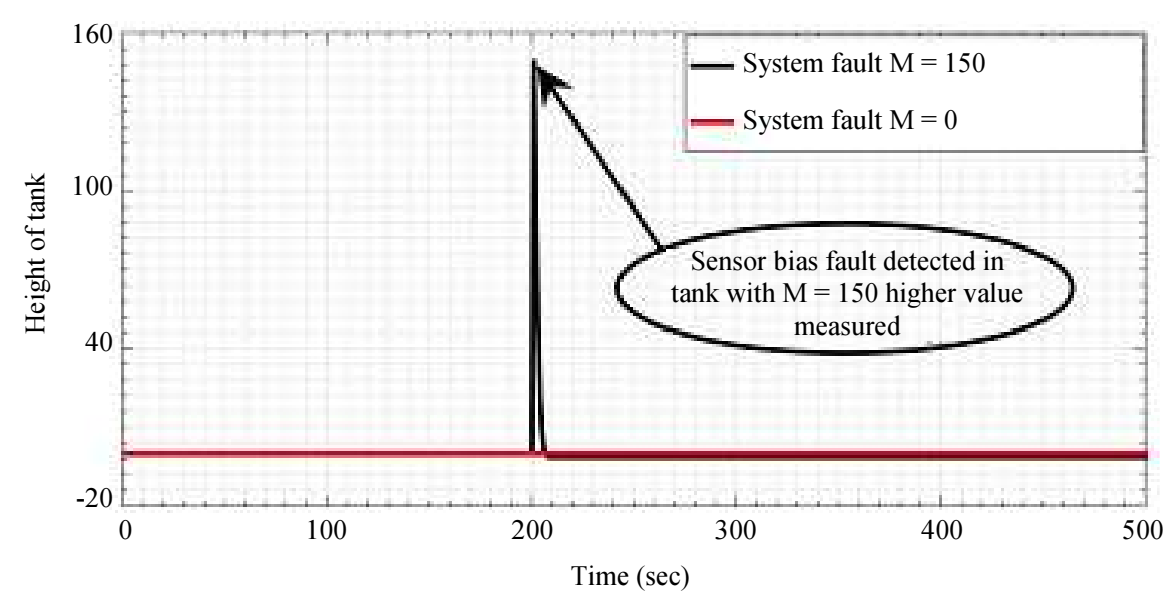

Fig. 9: System (Leak) and sensor bias faults detection in Single-Tank level control process with magnitude

Table 1: Fuzzy rules for passive FTC strategy

\begin{tabular}{ll}
\hline Rule No. & Fuzzy Rule \\
\hline 1. & If (Residue-Value is Very-Low) then (Control-Action is Very-Low) \\
2. & If (Residue-Value is Low) then (Control-Action is Low) \\
3. & If (Residue-Value is Medium) then (Control-Action is Medium) \\
4. & If (Residue-Value is High) then (Control-Action is High-Control) \\
5. & If (Residue-Value is Very-High) then (Control-Action is Very-High) \\
\hline
\end{tabular}

The single-tank system with the designed passive Fault-tolerant controller is simulated in MATLAB Simulink environment along with its real-time implementation. The system faults signal are generated at time $T=200 \mathrm{sec}, T=400 \mathrm{sec}$ and sensor bias faults are generated continuously. Figure 8 shows the Simulink block diagram in MATLAB platform, system (leak) and sensor fault generated in simulation with different magnitude at different time in single-tank level control system. The control strategies proposed here show their efficacy in results presented by figures 10 to 15 . Figure 7 shows the system and sensor fault detection on singletank system at time $\mathrm{T}=200 \mathrm{sec}$.

\section{Results and Discussion}

Figure 10 represents the output response of singletank system with system (leak) fault. After that Fig. 11 to 14 represents response of three schemes of PFTC on single-tank level control system with combination of system and sensor bias faults. The magnitude of the faults are changing and the effectiveness of the proposed PFTC strategy is determined. Two system fault and one sensor bias faults are applied and the efficacy of three PFTC configurations is verified which clearly shows that PFTC using PI +Fuzzy control gives better control performance as compared to two other PFTC configurations as shown in Fig 15. There are three control strategies implemented and amongst them one is from conventional PI control PFTC and two are from model based PFTC using artificial intelligence. Figure showing results provide comparison between all three control strategies on MATLAB Simulink platform. From these figures, it is obvious that when the conventional feedback PI controller is used and system and sensor faults occur, the performance of the system degrades extremely and the fault occurred has an enormous effect on the system yield. The PFTC using fuzzy control has compensated for the effect of fault and it has enhanced the system performance under the fault constraint. However, the output response of conventional PI control design does not achieve better performance in the circumstance when system and sensor faults occur in the system. It can be observed that the PFTC using fuzzy control design had achieved its desired set point and its stability with superior performance. Hence, the PFTC using fuzzy control strategy is able to overcome the system and sensor faults at the same time with different magnitude and it achieves the set point.

In the "Table 2" performance of the simulation of PFTC using conventional PID and fuzzy control controllers are compared using the different error indices. The different errors are calculated during the time period of system and sensor faults are generated and steady state achieved. In both cases the PFTC using fuzzy control has shown better performance even though multiple faults have occurred with different magnitudes. From the error indices value in "Table 2 " in $6^{\text {th }}$ case where two system (leak) and one sensor faults are introduced in single-tank level control system, proposed PFTC scheme shows their supremacy in control performance as compared to other control schemes. 


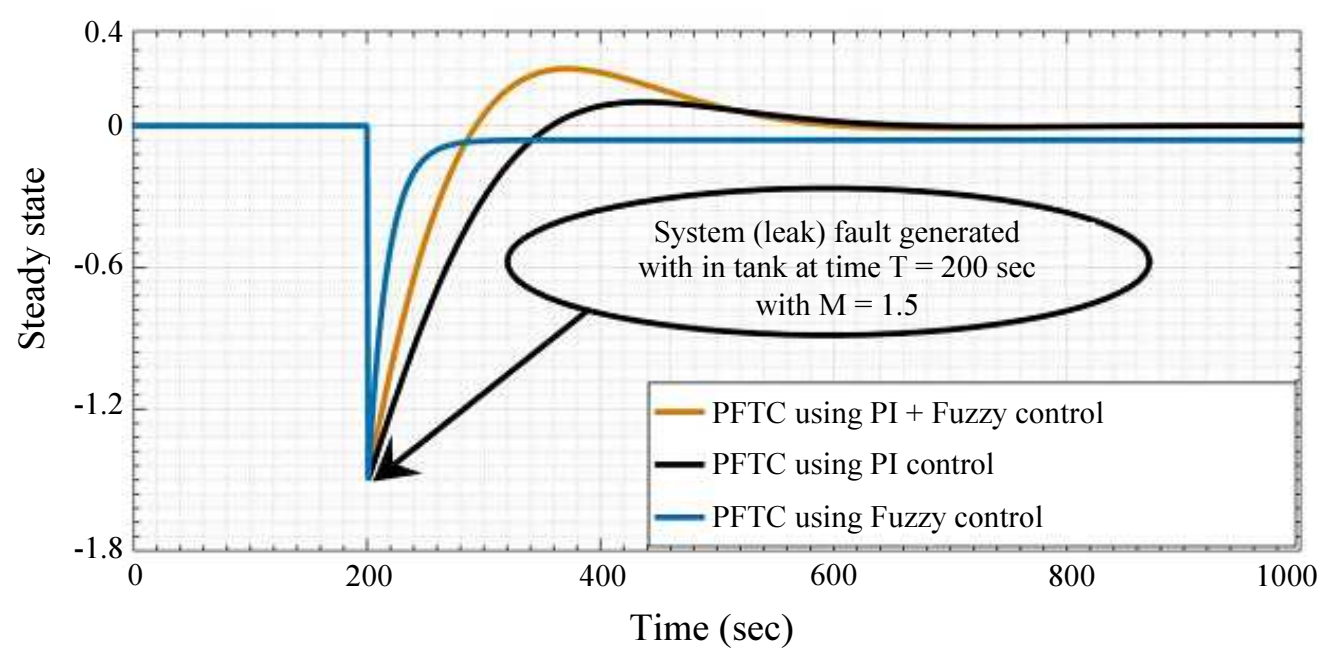

Fig. 10: PFTC strategy result comparison with system fault

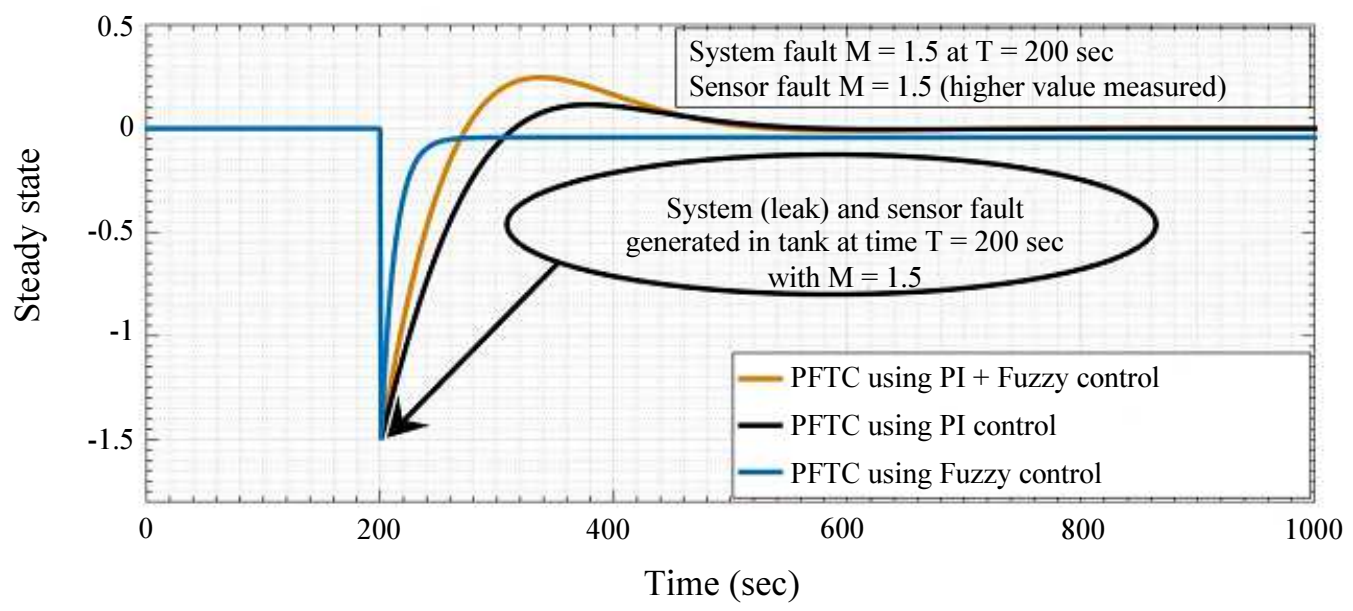

Fig. 11: PFTC strategy result comparison with system and sensor bias faults

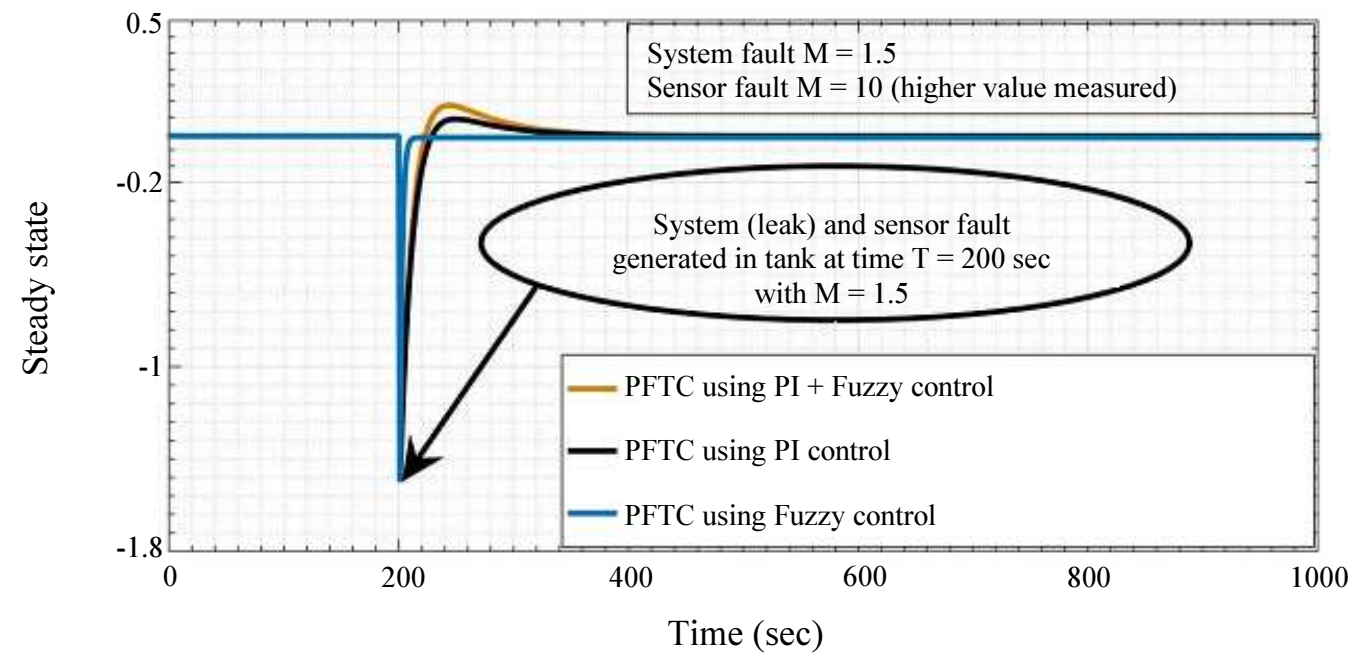

Fig. 12: PFTC strategy result comparison with system and sensor bias fault 


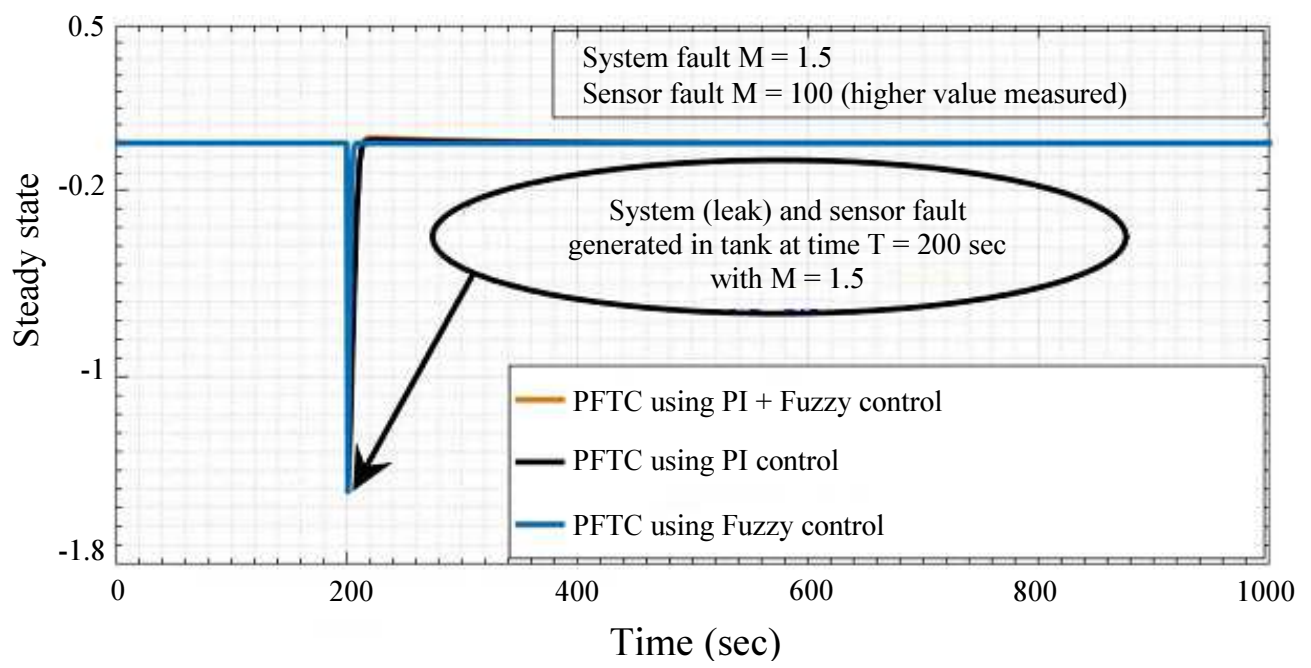

Fig. 13: PFTC strategy result comparison with system and sensor bias faults

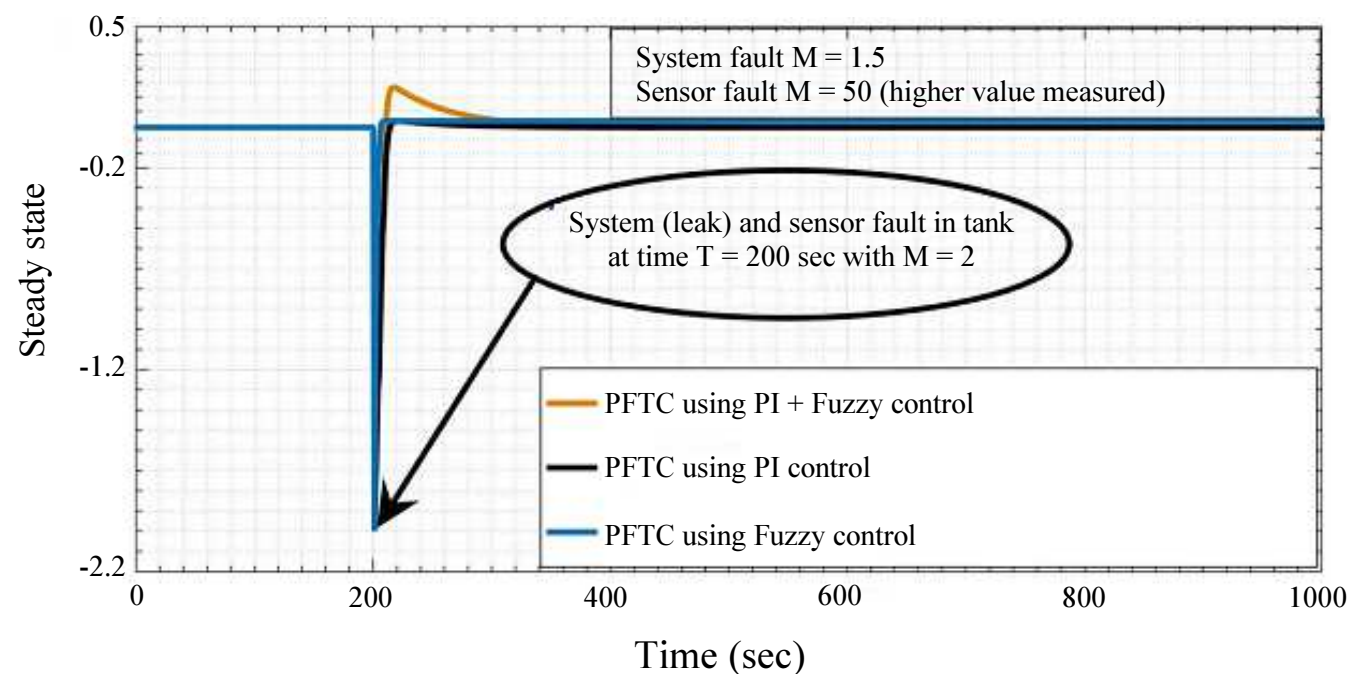

Fig. 14: PFTC strategy result comparison with system and sensor bias fault

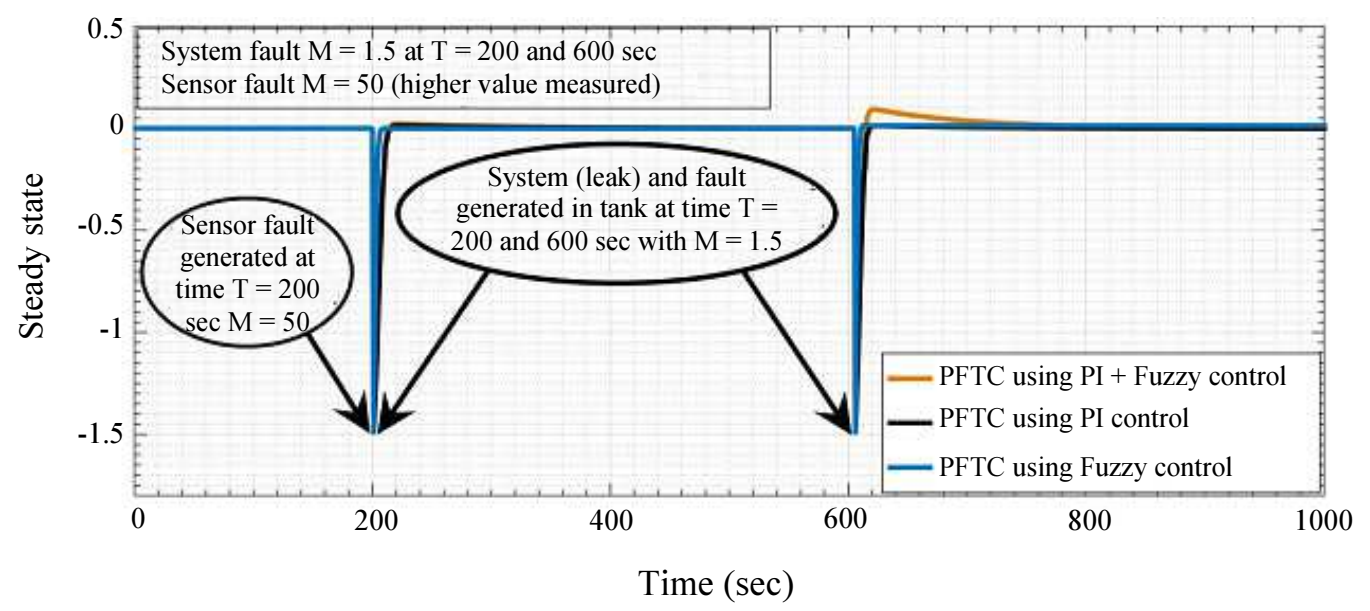

Fig. 15: PFTC strategy result comparison with two system and one sensor bias faults 
Table 2: Control performance results of three PFTC strategies using different controller with system and sensor bias faults

\begin{tabular}{|c|c|c|c|c|c|}
\hline \multirow{2}{*}{$\begin{array}{l}\text { Model-based PFTC strategy } \\
\text { using different controller }\end{array}$} & \multicolumn{2}{|c|}{ Faults in system with magnitude } & \multicolumn{3}{|c|}{ Error Indices } \\
\hline & System fault (Leak) & Sensor fault & MSE & RMSE & MAE \\
\hline FTC Using PI Control & $\checkmark \mathrm{M}=1.5$ & NA & 0.0570 & 0.2387 & 0.0722 \\
\hline FTC Using PI + Fuzzy Control & & & 0.0393 & 0.1983 & 0.0647 \\
\hline FTC Using Fuzzy Control & & & 0.0174 & 0.1319 & 0.0692 \\
\hline FTC Using PI Control & $\sqrt{ } \mathrm{M}=1.5$ & $\sqrt{ } \mathrm{M}=1.5$ & 0.0611 & 0.2472 & 0.0813 \\
\hline FTC Using PI + Fuzzy Control & & & 0.0470 & 0.2168 & 0.0784 \\
\hline FTC Using Fuzzy Control & & & 0.0165 & 0.1288 & 0.0522 \\
\hline FTC Using PI Control & $\checkmark \mathrm{M}=1.5$ & $\checkmark \mathrm{M}=10$ & 0.0079 & 0.0889 & 0.0124 \\
\hline FTC Using PI + Fuzzy Control & & & 0.0076 & 0.0872 & 0.0141 \\
\hline FTC Using Fuzzy Control & & & 0.0024 & 0.0490 & 0.0087 \\
\hline FTC Using PI Control & $\checkmark \mathrm{M}=1.5$ & $\checkmark \mathrm{M}=100$ & 0.0047 & 0.0686 & 0.0053 \\
\hline FTC Using PI + Fuzzy Control & & & 0.0046 & 0.0678 & 0.0059 \\
\hline FTC Using Fuzzy Control & & & 0.0019 & 0.0436 & 0.0027 \\
\hline FTC Using PI Control & $\checkmark \mathrm{M}=2$ & $\checkmark M=50$ & 0.0144 & 0.12 & 0.0126 \\
\hline FTC Using PI + Fuzzy Control & & & 0.0144 & 0.12 & 0.0207 \\
\hline FTC Using Fuzzy Control & & & 0.0061 & 0.0781 & 0.0295 \\
\hline FTC Using PI Control & $\checkmark \mathrm{M}=1.5$ (At T & $\checkmark \mathrm{M}=100$ & 0.0098 & 0.099 & 0.011 \\
\hline FTC Using PI + Fuzzy Control & $=200$ and $400 \mathrm{Sec})$ & & 0.0098 & 0.099 & 0.015 \\
\hline FTC Using Fuzzy Control & & & 0.0041 & 0.0640 & 0.0125 \\
\hline
\end{tabular}

From observing the PFTC responses of single-tank level control system with two faults, by checking efficacy of the proposed system under two fault constraints. The sensor fault rejection capability of the PFTC strategy is more as compared to system (leak) fault rejection. At the same time the setpoint tracking capability of the PFTC strategy is better compare to other control schemes. However the actuator and controller faults are not considered at the time of designing the PFTC scheme and at simulation. The proposed PFTC scheme is capable to accommodate the process disturbances which are not covered during simulation. To accommodate the actuator and controller faults in PFTC strategy, prior information are required at the time of controller design level and thereafter it will accommodate these faults according to the prior information and knowledge.

\section{Conclusion}

This article attributes the proposed model based PFTC strategy using conventional feedback and artificial intelligence (Fuzzy Control) for system and sensor faults in single-tank level process. The applied design provides control strategies that are capable to maintain stability as well as performance when different faults occur. From the simulation results, when fault occurs, the PFTC using fuzzy control design has achieved its desired set point and stability. Meanwhile, the PFTC using PI feedback control design achieves its desired set point but is unable to reduce its steady state error as compared to PFTC using fuzzy control. Hence, it can be proved that PFTC using fuzzy control design is one of the most efficient techniques to ensure that the system performance does not degrade and set point is achieved even in presence of faults. The effectiveness of the proposed fault- tolerant control strategy was established on MATLAB Simulink platform. In further works instead of conventional PI controller model predictive controller (MPC) can be be applied on experimental setup and check the performance of the PFTC with multiple faults (Sensor, actuator, valve chocking). Also instead of fuzzy logic, other soft computing methods can be used (Artificial Neural Network (ANN), Adaptive Neuro Fuzzy Inference System (ANFIS)) for designing FTC strategy.

\section{Acknowledgement}

The partial work was carried out in Instrumentation and Process Control (IPC) Laboratory at the Department of Chemical Engineering, Dharmsinh Desai University, Nadiad-387001, Gujarat, India. We would like to express our heartily appreciation to Dr. M. S. Rao for his valuable and constructive suggestions during the planning and development of this research work. We would also like to express sincere gratitude to the Editor-in-chief and anonymous reviewers whose constructive comments have helped us to significantly improve both the technical quality and presentation of this paper.

\section{Funding Information}

All costs for the preparation, writing and publication of the article are provided by the corresponding author of the paper. 


\section{Author's Contributions}

Himanshukumar R. Patel: He designs the experiments, performed the simulation of the system and writes the manuscript.

Dr. Vipul A. Shah: He guide and gives the constructive suggestion during the simulation work. Also he gives valuable suggestion in the form of technical part of the manuscript.

\section{Ethics}

In this article, all ethical principles related to scientific research articles such as validity and authenticity, originality, data collection in a standard manner, integrity and accuracy of research, etc. are observed.

\section{References}

Aberkane, S., J.C. Ponsart and D. Sauter, 2008. Outputfeedback $\mathrm{H} 2 / \mathrm{H} \infty$ control of a class of networked fault tolerant control systems. Asian J. Control, 10: 34-44. DOI: 10.1002/asjc.4

Basin, M., L. Li, M. Krueger and S.X. Ding, 2015. A finite-time-convergent fault-tolerant control and its experimental verification for DTS200 three-tank system. Proceedings of the International Workshop on Recent Advances in Sliding Modes, Apr. 9-11, IEEE Xplore Press, Istanbul, Turkey, pp: 1-6.

DOI: 10.1109/RASM.2015.7154633

Blanke, M., M. Kinnaert, J. Lunze and M. Staroswiecki, 2006. Diagnosis and Fault-Tolerant Control. 2nd Edn., Springer, New York, ISBN-10: 3540356533, pp: 672.

Capiluppi, M. and A. Paoli, 2005. Distributed fault tolerant control of the two-tanks system benchmark. Proceedings of the 44th IEEE Conference on Decision and Control, Dec. 15-15, IEEE Xplore Press, Seville, Spain, pp: 7674-7679.

DOI: 10.1109/CDC.2005.1583401

Casavola, A., D. Famularo, G. Franzè and A. Furfaro, 2010. A fault-tolerant real-time supervisory scheme for an interconnected four-tank system. Proceedings of the American Control Conference, Jun. 30-Jul. 2, IEEE Xplore Press, Baltimore, MD, USA, pp: 6210-6215. DOI: 10.1109/ACC.2010.5531619

Dardinier-Maron, V., F. Hamelin and H. Noura, 1999. A fault-tolerant control design against major actuator failures: Application to a three-tank system. Proceedings of the 38th Conference on Decision and Control, Dec. 7-10, IEEE Xplore Press, Phoenix, AZ, USA, pp: 3569-3574.

DOI: $10.1109 /$ CDC.1999.827906

Diaoa, Y. and K.M. Passino, 2002. Intelligent faulttolerant control using adaptive and learning methods. Control Eng. Practice, 10: 801-817.

DOI: 10.1016/S0967-0661(02)00032-1
Ding, P.M., 1997. Survey of robust residual generation and evaluation methods in observer-based fault detection systems. J. Process Control, 7: 403-424. DOI: 10.1016/S0959-1524(97)00016-4

Gao, Z., C. Cecati and S.X. Ding, 2015. A survey of fault diagnosis and fault-tolerant techniques-Part I: Fault diagnosis with model-based and signalbased approaches. IEEE Trans. Industrial Electron., 62: 3757-3767. DOI: $10.1109 /$ TIE.2015.2417501

Hussain, M.A., C.R.C. Hassan K.S. Loh and K.W. Mah, 2007. Application of artificial intelligence techniques in process fault diagnosis. J. Eng. Sci. Technol., 2: 260-270.

Isermann, R., 2006. Fault-Diagnosis Systems: An Introduction from Fault Detection to Fault Tolerance. 1st Edn., Springer Science and Business Media, New York, ISBN-10: 3540303685, pp: 475.

Jiang, J., 2010. Why does one need fault-tolerant control systems anyway? Proceedings of the Conference on Control and Fault Tolerant Systems, Oct. 6-8, IEEE Xplore Press, Nice, France, pp: 118-118. DOI: $10.1109 /$ SYSTOL.2010.5675943

Korbicz, J., J.M. Koscielny, Z. Kowalczuk and W. Cholewa, 2004. Fault Diagnosis: Models, Artificial Intelligence, Applications. 1st Edn., SpringerVerlag, ISBN-10: 3540407677, pp: 920.

Li, H.X. and Y.H. Wang, 2014. Active fault tolerant control of CSTR system based on MLD model. Proceedings of the 26th Chinese Control and Decision Conference, May 31-Jun. 2, IEEE Xplore Press, Changsha, China, pp: 3146-3149.

DOI: 10.1109/CCDC.2014.6852716

Mendoca, L.F., João Sousa and José M. G. Sá da Costa, 2007. Fault tolerant control of a three tank benchmark using weighted predictive control. Proceedings of the 12th International Fuzzy Systems Association World Congress, Jun. 18-21, Cancun, Mexico, pp: 732-742.

DOI: $10.1007 / 978-3-540-72950-172$

Mendonca, L.F., J.M.C. Sousa and J.M.M.G. Sa da Costa, 2008. Fault accommodation of an experimental three tank system using fuzzy predictive control. Proceedings of the IEEE International Conference on Fuzzy Systems, Jun. 1-6, IEEE Xplore Press, Hong Kong, pp: 1619-1625.

DOI: 10.1109/FUZZY.2008.4630588

Niederlinski, A., 1971. A heuristic approach to the design of linear multivariable interacting control systems. Automatica, 7: 691-701. DOI: 10.1016/0005-1098(71)90007-0

Noura, H., D. Theilliol and D. Sauter, 2000. Actuator fault-tolerant control design: Demonstration on a three-tank-system. Int. J. Syst. Sci., 31: 1143-1155. DOI: $10.1080 / 002077200418414$ 
Orani, N., A. Pisano and E. Usai, 2009. Fault detection and reconstruction for a three-tank system via highorder sliding-mode observer. Proceedings of the IEEE Control Applications, (CCA) and Intelligent Control, Jul. 8-10, IEEE Xplore Press, St. Petersburg, Russia, pp: 1714-1719. DOI: 10.1109/CCA.2009.5281085

Parikh, N., S. Rathore, R. Misra and A. Markana, 2017. A comparison between NMPC and LQG for the level control of three tank interacting system. Proceedings of the Indian Control Conference, Jan. 4-6, IEEE Xplore Press, Guwahati, India, pp: 200-205. DOI: 10.1109/INDIANCC.2017.7846475

Patel, H.R. and V.A. Shah, 2018. Fault tolerant control systems: A passive approaches for single tank level control system. J. Instrument. Control, 6: 11-18. DOI: $10.26634 /$ jic.6.1.13934
Puig, V., F. Schmid, J. Quevedo and B. Pulido, 2005. A new fault diagnosis algorithm that improves the integration of fault detection and isolation. Proceedings of the 44th IEEE Conference on Decision and Control and the European Control Conference, Dec. 15-15, IEEE Xplroe Press, Seville, Spain, pp: 3809-3814. DOI: 10.1109/CDC.2005.1582755

$\mathrm{Xu}, \mathrm{D} ., \mathrm{B}$. Jiang and P. Shi, 2015. Robust NSV faulttolerant control system design against actuator faults and control surface damage under actuator dynamics. IEEE Trans. Industrial Electron., 62: 5919-5928. DOI: 10.1109/TIE.2015.2450714

Zhang, Y. and J. Jiang, 2008. Bibliographical review on reconfigurable fault tolerant control systems. Annual Rev. Control, 32: 229-252.

DOI: $10.1016 / \mathrm{j}$.arcontrol.2008.03.008 